\title{
A three-dimensional model that helps tutors to monitor groups during a collaborative online work
}

\author{
M. Salihoun ${ }^{\# 1}$, F. Guerouate ${ }^{\# 2}$, M. Sbihi ${ }^{\# 3}$ \\ * Laboratory of Systems Analysis and Information Processing, \\ Mohammed V University, Rabat, Morocco \\ ${ }^{1}$ salihoun.med@gmail.com \\ 2.guerfat@yahoo.fr \\ ${ }^{3}$ mohamed.sbihi@yahoo.fr
}

\begin{abstract}
The E-Learning, model, based on learner's activity, can provide proof for competence assessment. Such models are the foundation for learning and teaching support, such as adaptation, assessment, competence analysis, recommendations and so on. This paper describes a method for analysing the learning processes that takes place in a computer-supported collaborative learning (CSCL) environment. Our approach is based on tracking the interactions between learners within groups and on a three-dimensional model that includes a participative, an interactive and an affective dimension. The exploitation of these traces can serve three main purposes: the evaluation of the quality of the process, the monitoring of student's performance in real time and the assessment of collaborative learning performances. In this study, the importance of a good climate of trust and affection in promoting teamwork is presented. In addition, a set of indicators is obtained by tracking course learner's behaviour within the learning environment. The findings of an empirical study of 14 work-based teams are discussed. The results can benefit to the tutor by providing him the opportunity to rebuild the working groups based on the stable and variable characteristics of learners.
\end{abstract}

Keyword-E-learning, Traces, Indicators, Sociograms, Online collaborative work

\section{INTRODUCTION}

Usually, courses in online learning platforms are structured in various phases. In each phase, learners are required to engage in collaborative activities aimed at producing the work requested by their tutors. In order to do so, they will need to discuss, collaborate, negotiate meanings and finally reach an agreement in order to reify a shared product that is the expression of the group's achievements. However, tutors often struggle to track learners/groups progress or to detect learners/groups experiencing difficulties [1]. In order to have a deep understanding of the learning process, tutors are required to go beyond the surface level of interactions in order to understand the social and the cognitive processes involved. As computer conferencing systems usually record and maintain a history of the events occurring during the learning process, a wealth of information that can be analyzed is available.

Several research studies over the last decades are leaning towards the track analysis in online learning environments. The main objective of this research is to guide tutors to interpret the learner's activities in elearning situations, by exploiting and analyzing the traces and providing knowledge on the activities, which we call learning indicators. These indicators help to understand and monitor learning in order to help tutors and offer them the opportunity to rebuild the working groups accusing difficulties based on the stable and variable characteristics of learners.

Unfortunately, in our last study [1], some learners did not produce nothing due to an absence of a cohesion in the group. These include the problems of the affective dimension of learners, convergence problems and those of perception of the group. All these factors can negatively affect the process of discussion, sharing and collaboration. According to these problems, it is strongly recommended that the organizational culture, which behavior and promotes trust should be encouraged in teamwork by elaborating sociograms in order to have information about emotional states, feelings and learners affects.

The second section provides a view of the motivations that led to this work. Some related works that have been achieved in the same context are discussed in the third section. The fourth section introduces the approach and the methodology intended. Finally, the experimental results, which validate this approach, are provided in the last section. 


\section{Motivations}

The traces have become the essential support to the observation of activities within an ITS. However, in many ITS environments, different actors (e.g. designer activity, tutor, learner, etc.) may be concerned by the use of traces and their exploitations. The goals of observation and the exploitation of traces of interactions are different depending on the category of each actor and the roles they have. In this paper, we will focus on the concept of traces as observation support for the teacher-tutor.

Several research studies have focused on the ITS, and raised the lack for awareness of activity by the tutor compared to the learner's activity [3][4]. These studies show that in such environments, the tutor usually gets much less information on the progress of the session than in a classic learning situation. On the one hand, the teacher has great difficulties to perceive the activity and to detect learners and working groups that are in difficulty. On the other hand, items from the perception of activity can be used by the teacher from the traces that are very variable and are often linked to the goal of the educational activity being observed. For example, recovery of information related to learner's performance (e.g. number of exercises completed, a score obtained in QCM) can help the tutor to identify difficulties encountered by learners or any malfunctions compared to the expected evolution the session [5]. Also, by elaborating sociograms, tutors can measure the cohesion of a group learning and assess the degree of collaboration and trust within these groups to see if learners collaborate in the best possible way [6][7].

The exploitation of interaction traces left by students in the Intelligent Tutoring System and the development of indicators are able to help the tutor to follow up the activities of his learners. Group formation often occurs in a random or according to criteria set by the tutor, so this sometimes leads groups are not homogeneous, hence the neglect and isolation of learners during training.

\section{III.RELATED WORKS}

Several research studies have focused on visualization techniques and applied this in various domains [8], including automotive industry [9] and finance [10]. In this paper, we focus on the Intelligent Tutoring System (ITS) domain. The literature on ITS has several platforms and tools for the use of individual and collaborative learning, for example:" Hardy et al. [11] visualize the path taken through resources. These visualizations are in essence directed graphs, with nodes representing pages and edges representing access between pages. GISMO (Graphical Interactive Student Monitoring System for Moodle) [12] visualizes accesses to a course and its resources. Among others, the application relies on a simple matrix visualization of student names and resource names to represent resource accesses. CAMera [13] analyzes user activities and provides simple metrics of events, such as mouse clicks. The system relies on Contextualized Attention Metadata (CAM) [14] that captures user interactions with tools and resources. Moodog [15] visualizes metrics of students' online learning activity logs in Moodle using bar charts. In addition, SAM project [16] analyzes user events to extract indications of the time learners have spent on learning activities. It provides visual analysis of time learners spent on learning activities and document use statistics enabling more analysis that is detailed.

Other indicators are qualitatively interpreted as Martinez [17] in which they interpret the indicator of the density of the social network by histograms. Gagnon [18] provide a conceptual framework that integrates and measure the affective dimension in a pedagogical training. Sugawara and Arai [19] have developed a visualization module, named Collabo-MAP, which provides NetCommons with a tool for graphically mapping student-student and teacher student interactions in online forums. Other research studies are also used to calculate indicators using quantitative data [20] such as the calculation of cohesion and centrality in social networks and discussion forums. Jaillet [21] offers the tutor, via his platform ACOLAD, a tool that provides information on a triplet of the activity (presence, availability, participation). Santos [22] provide a tool, which performs calculations starting from the interactions and the degree of involvement of each learner in training.

All these studies show the importance of methods and the context of the development of indicators from traces of interactions related to the learning activity. Our approach focuses on finding a better climate of trust and affection in promoting teamwork by elaborating sociograms and analysing traces. Also to produce and exploit indicators in order to help and assist tutors to rebuild the groups are not homogeneous.

\section{IV.METHODOLOGY}

Five generic social plans were identified by Dillenbourg [23] that structure or influence learning activities: the individual plan, the group plan, the class plan, the community plan and the world plan. The individual plan refers to solo activities. The group plan refers to activities in small groups that allow direct collaboration among all participants. The class plan includes activities that involve all participants from the same course. The community plan involves actors from other classes or courses on the same topic. Finally, the world plan refers to actions that involve unidentified actors, such as visitors of a public web-journal. Information of different social plans can support self-assessment activities in TEL as identified by Glahn, Specht and Koper [24]. 
Our methodology is based on the study of traces as observation support for the teacher-tutor left in the online learning platform, specifically the discussion forum and the internal mail. In this context, several indicators can be built to observe and operate participative, interactive and affective processes implemented. Indeed, exploiting traces allows building several types of indicators [25][26].

The three-dimensional model proposed in this paper does not compulsorily imply the use of all three dimensions: depending on the specific aims of the analysis, one may decide which dimensions are most relevant. For example, when a tutor is monitoring the learners' level of participation, he or she is most likely to be interested in the participative and the interactive dimensions. On the contrary, all the dimensions are worth investigating when the purpose is to validate the overall learning experience.

In our last study, we have eliminated the affective dimension of our typology, because the exploitation of traces of interaction during a learning activity does not inform directly about the emotional state and the feelings, which affect learners. The last experiment results show that some learners may produce nothing if there is an absence of cohesion within their groups. These issues include the affective dimension of learners, convergence problems and perception of the group [2]. All these factors can negatively affect the process of discussion, sharing and collaboration.

\section{A. The Affective Dimension}

In social environments, there are affective functions that intervene in building relationships within a group. Empathy, emotions, motivations and relationship management are aspects that appear in a communication or collaboration context. Affective indicators are seeking to characterize the more or less personal interaction. The qualities and effective skills are involved significantly in building relationships within a group.

In order to investigate social presence, it is necessary to identify cues that demonstrate affection and cohesiveness within communication acts. According to Hollander [27], people are bound by three possible relationships: sympathy, antipathy and indifference. These relationships can be measured using a questionnaire.

Analysis of the results allows modeling a system (the group and its members). This system is established from a questionnaire called the Sociogram.

The questionnaire for learners is based on three questions:

- Who is the first person with whom you would like to work?

- Who is the second person with whom you would like to work?

- Who is the person who you would not like to work with?

- The sociogram should be used in conjunction with training rules work teams:

- Above all, we decide the size of the groups.

- We begin by placing the isolated individuals, ideally with their first choice. Otherwise, they are placed with their first two choices. Never put more than two isolated in each team.

- Then, we place the learners who received only one choice. If the choice is reciprocal, the learner is placed with the individual who makes this reciprocity.

- We continue the distribution on the basis of learners who receive the smallest to the largest number of choices. Ideally, we try to satisfy mutual choice first.

While Garrison et al. [28] include Interaction as an indicator of social presence; we agree with Henri [29] and consider it worth addressing separately.

\section{B. The Participative Dimension}

Taking part in an online collaborative experience, the level of students' participation in a learning experience gives a rough but important indication of their involvement in the learning process. For this reason, investigation of the participative dimension may help the tutor to tune the activities, inform the assessment procedures and be used as a first element of the overall evaluation of the learning experience.

In our experimentation, we have implemented three categories of indicators needed to investigate the participative dimension:

- Indicators of active participation, which include the number of messages sent by individual participants, the number of documents uploaded, the number of chat sessions and forums attended, etc.;

- Indicators of passive participation, which include the number of messages read, the number of documents downloaded, etc.;

- Indicators of continuity, which is the distribution of participation along time. 


\section{The Interactive Dimension}

In CSCL contexts, interaction refers to the relationships that participants build during the learning processes. Dillenbourg [23] defines the degree of interactivity between pairs as reciprocal influences in the cognitive process. From this point of view, an investigation of the interactive dimension should address aspects such as cross-reference to others' messages and documents or co-production of artefacts.

In our experimentation, we have implemented two categories of indicators needed to investigate the interactive dimension and are drawn from quantitative and qualitative content analysis of messages and documents exchanged by students during the learning process:

- Indicators of Passive participation before posting, which is the number of relevant messages read by a student before posting his/her own, the number of documents downloaded before posting, etc.

- Indicators of References to other student's messages, which is the number of answers to other student's messages, the number of implicit or explicit citations of other student's messages, etc.

\section{Data for tracking learning processes}

In CSCL systems, the interactions between participants are usually recorded in an automatic way and are a very important source of data. All the dimensions cited above, as well as their indicators, can be investigated by the collection and manipulation of these types of data. They contain messages and documents exchanged, their 'history' (sending and reading timestamps, name of sender, name of readers, etc.) and log files. Other kinds of data can be gathered through questionnaires, interviews, etc... In [30], data with quantitative nature can be easily processed by means of statistical methods and tools. Otherwise, in [31], data can be determined by quantitatively elaborating the results of qualitative analysis of textual data.

Examples of raw data are: the number of sessions for each participant (with starting and ending time), the number of messages sent (sorted according to participant, area/conference, given periods, etc.), the size of messages sent by each participant, the number of messages read by each participant, the number of threads activated by students and by tutors, the number of produced documents, the number of chats, etc.

Online courses usually make use of CMC platforms with a client-server architecture: participants use a client application (a web browser or some proprietary application) to connect to a centralized server program, which relies on a database to provide access to messages, user directories, discussion areas, etc. (e.g. Centrinity FirstClass, http://www.centrinity.com/; Moodle, http://www.moodle.org/). Server programs record significant events in $\log$ files, which are the most widespread method of collecting raw data.

Tracking of raw data and subsequent analysis of log files - this is usually carried out by means of specialized software (e.g. Nihuo Web Log Analyzer, http://www.loganalyzer.net/; Web Log Expert, http://www.weblogexpert.com/; Visitors, http://www.hping.org/visitors/; Web Log Explorer, http://www.exacttrend.com/WebLogExplorer/) — is often used by tutors for gaining on-the-fly information about the participative dimension (e.g. summarizing participation to identify inactive students or lurkers, providing personalized feedback, supporting meta-cognitive reflection, and so on).

In our case, data collection was limited to the extraction of information from the Moodle database, log files and the development of quantitative indicators mentioned before, but also to safeguard the jobs posted by learners at the end of their learning processes.

\section{EXPERIMENTATION}

\section{A. Research Subjects and Period}

This experimentation enters into the curriculum of studies in the first year at the Moroccan School of Engineering Sciences in Rabat. The experimentation was an opportunity to make learners remotely achieve via distance learning platform Moodle [32] a common project, in connection with the Object Oriented Programming in $\mathrm{C}++$. This work lasted ten weeks coinciding with the end of the course during the two last weeks. This time, we chose to stimulate students to do online work only.

\section{B. Tools disposed in platform}

The project was conducted on the Moodle platform. Learners had at their disposal:

- A detailed description of the specifications of the project. (The general context of the project, the functional and technical description, the resources and the time of implementation, etc...).

- Online resources on the Moodle platform (lectures, articles, tutorials and corrected practices, Internet links, etc...).

- A structured forum for each group where learners can discuss different tasks.

- An area of synchronous chat for each group. 


\section{Constitution of groups}

The 84 persons involved in this experiment were students of the first year option: Computer and Networks Engineering, of the Moroccan School of Engineering Sciences in Rabat. They were divided into teams of 6 members. Learners have all followed a traditional course of Object Oriented C++ programming. The project was set according to the specifications provided by the tutor. The work that these learners had to carry on the Moodle platform was taken into account in their final grade on the " $\mathrm{C}++\mathrm{OOP}$ " module.

During the experiment, the groups were not formed in an arbitrary way. The learners were free to choose whom to work with. There exists a subjective element to take into account. If, in a class, we can form groups composed of members who get along with each other, this affinity will probably improve the morale of the whole class and thus its productivity. The composed groups will use less energy in debating during their internal interactions.

The learners had at their disposal a questionnaire to be submitted to the tutor. The questionnaire contained three questions cited previously.

D. Questionnaire results



Fig. 1. Sociogram of learners who had mutual choice concerning the first question

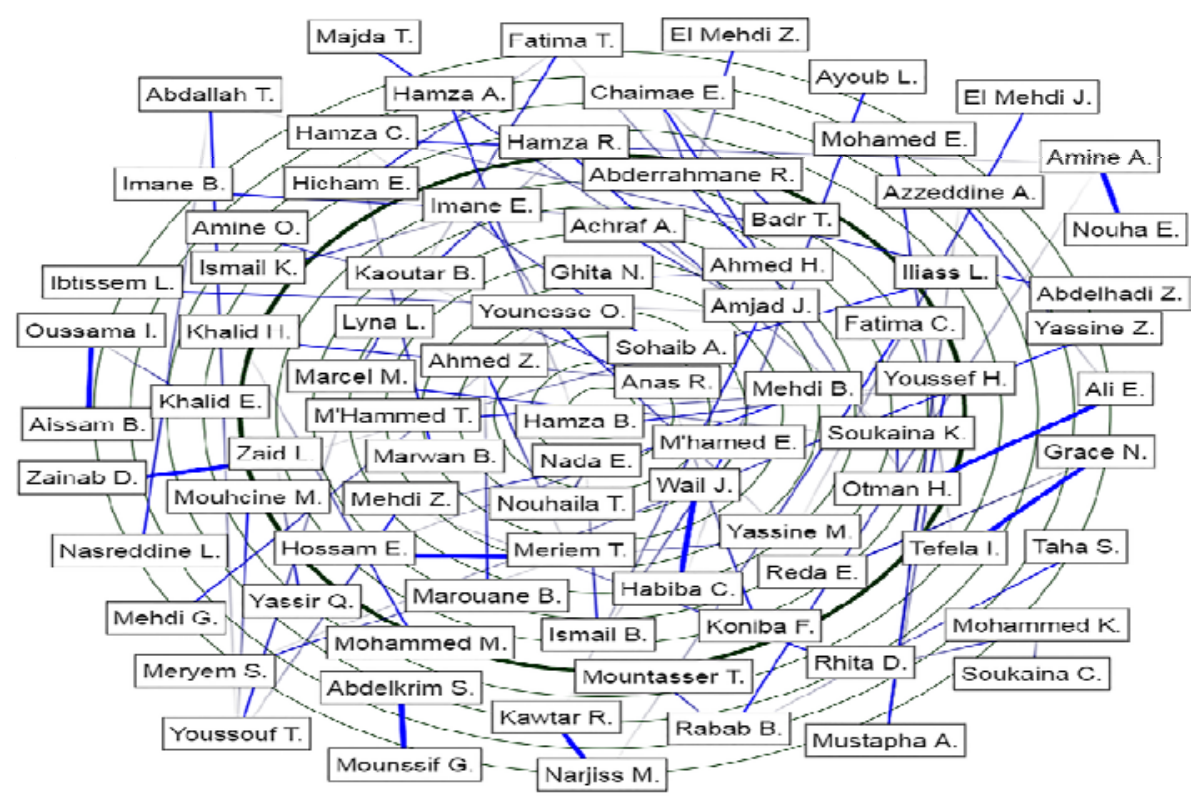

Fig. 2. Sociogram of learners who had mutual choice concerning the second question 


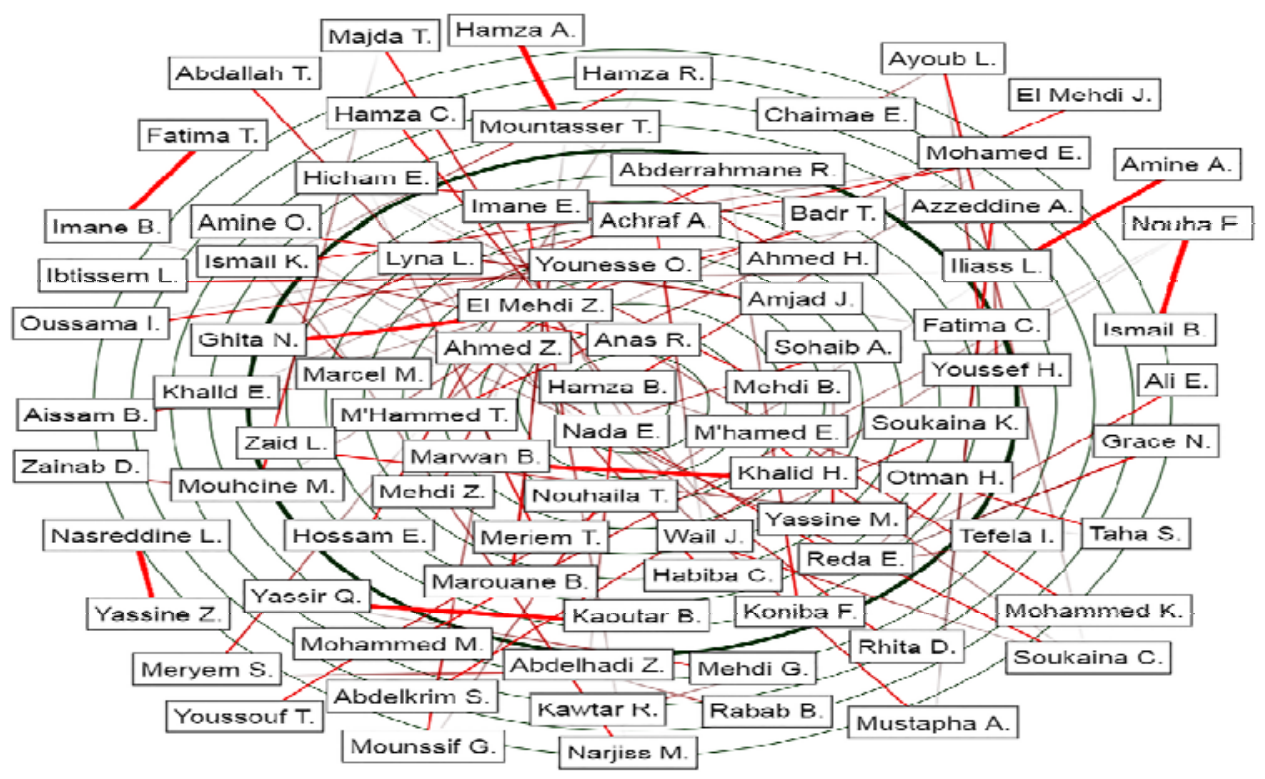

Fig. 3. Sociogram of learners who had mutual choice concerning the last question

The learner's responses to the questionnaire allowed us to construct a sociogram and groups that should be used in conjunction with training rules work teams cited before. Fig 1 . Show us the relation between learners who had a mutual choice in the first question. (Who is the first person with whom would you like to work?). Fig 2. Shows us the relation between learners who had a mutual choice concerning the second question (Who is the second person with whom you would like to work?). Fig 3. Shows us the relation between learners who had a mutual choice concerning the last question (Who is the person who you would not like to work with?).

Based on the rules of formation of working groups, the distribution of learners on groups is shown in Table I.

\section{E. Evolution of groups}

The first crucial remarks that are valid for all groups is that during the three first weeks, learners often log in to the platform and participate in the discussion forum and chat sessions following the indicators: "Distribution of participation along time", "Number of chat sessions" and "Number of forums attended". This period did not see much sharing and document submissions on the forums of each group, as shown in the indicators: "Number of documents uploaded" and "Number of documents downloaded". From the fourth week, we have seen a large number of messages exchanged on the forums and the internal mail of each group as shown in Table II and described in Figure 4. Thus, we could detect learners who can play the role of leaders in their groups based on the indicators: "Number of answers to other student's messages", "Number of messages sent by individual learners" and "Number of documents shared".

TABLE I. The distribution of learners in groups according to the result of the sociogram

\begin{tabular}{|c|c|}
\hline Groups & Members \\
\hline Group 1 & Hamza B. - Otman H. - Ali E. - Mohamed M. - Youssouf T. - Imane B. \\
\hline Group 2 & Mounssif G. - Abdelkrim S. - Mohammed K. - Kaoutar B. - Fatima T. - Soukaina C. \\
\hline Group 3 & Hossam E. - Meriem T. - Meryem S. - Mehdi B. - Imane E. - Ismail K. \\
\hline Group 4 & Nouha E. - Amine A. - Hicham E. - Mountasser T. - Hamza C. - Achraf A. \\
\hline Group 5 & Nouhaila T. - Nada E. - M'hammed T. - Ahmed H. - Badr T. - Mehdi G. \\
\hline Group 6 & Zainab D. - Nasreddine L. - Zaid L. - Abderrahmane R. - Yassir Q. - Iliass L. \\
\hline Group 7 & Lyna L. - Ibtissem L. - Soukaina K. - Marcel M. - Hamza R. - Hamza A. \\
\hline Group 8 & Yassine M. - Reda E. - Youness O. - Fatima C. - El Mehdi J. - Grace N. \\
\hline Group 9 & Majda T. - Abdallah T. - Mehdi Z. - Marouane B. - Sohaib A. - Taha S. \\
\hline Group 10 & Yassine Z. - Abdelhadi Z. - Mouhcine M. - Khalid H. - El Mehdi Z. - Rhita D. \\
\hline Group 11 & Koniba F. - Tefela I. - Rabab B. - Ghita N. - Khalid E. - Anas R. \\
\hline Group 12 & Habiba C. - Wail J. - Ayoub L. - Mohamed E. - Amine O. - Ahmed Z. \\
\hline Group 13 & Aissam B. - Oussama I. - Chaimae E. - Mustapha A. - Youssef H. - Marwan B. \\
\hline Group 14 & Narjiss M. - Kawtar R. - Ismail B. - M'hamed E. - Azzeddine A. - Amjad J. \\
\hline
\end{tabular}


TABLE II. The Number of messages exchanged and documents shared for each group during the first five weeks

\begin{tabular}{|c|c|c|c|c|c|}
\hline Groups & Week 1 & Week 2 & Week 3 & Week 4 & Week 5 \\
\hline Group 1 & 3 & 2 & 1 & 7 & 6 \\
\hline Group 2 & 2 & 3 & 2 & 5 & 9 \\
\hline Group 3 & 2 & 5 & 4 & 6 & 11 \\
\hline Group 4 & 1 & 4 & 6 & 8 & 7 \\
\hline Group 5 & 4 & 3 & 3 & 6 & 10 \\
\hline Group 6 & 1 & 4 & 2 & 9 & 9 \\
\hline Group 7 & 6 & 7 & 2 & 11 & 6 \\
\hline Group 8 & 1 & 4 & 1 & 7 & 9 \\
\hline Group 9 & 2 & 1 & 2 & 8 & 11 \\
\hline Group 10 & 2 & 3 & 5 & 10 & 6 \\
\hline Group 11 & 4 & 2 & 7 & 9 & 8 \\
\hline Group 12 & 6 & 3 & 4 & 6 & 6 \\
\hline Group 13 & 1 & 4 & 1 & 9 & 6 \\
\hline Group 14 & 3 & 2 & 3 & 11 & 8 \\
\hline
\end{tabular}

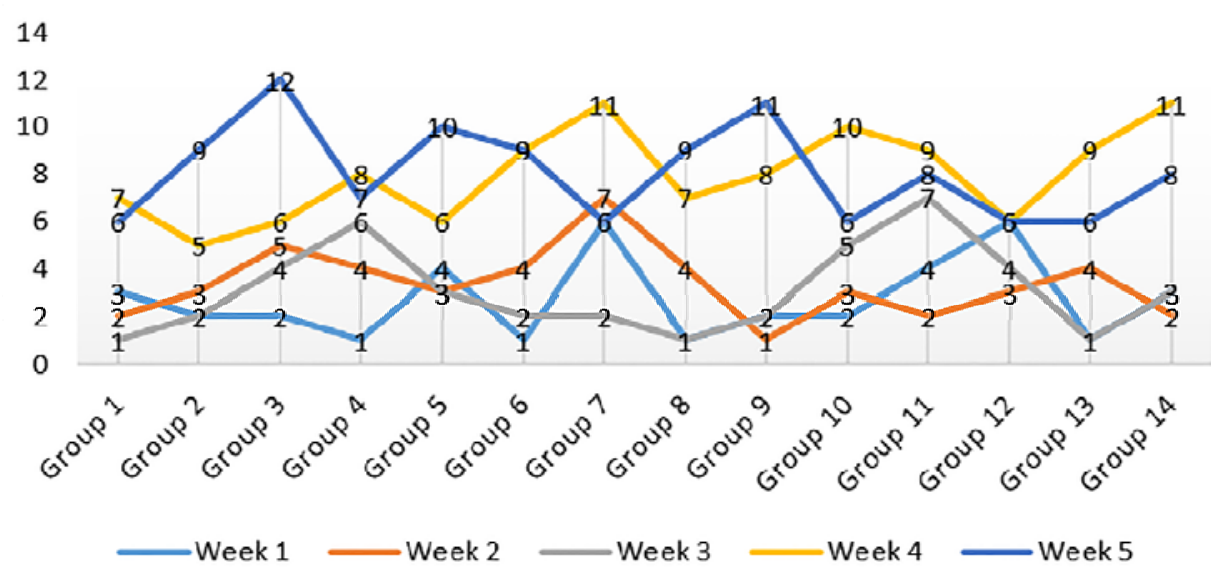

Fig. 4. The Number of messages exchanged on the forums and the internal mail for each group

Based on the three last indicators, it was found that learners as: (Marcel M. \& Hamza R., Group 7); (Koniba F. \& Ghita N., Group 11); (Meriem T. \& Imane E., Group 3); (Amine A. \& Achraf A., Group 4); (M'hammed T. \& Badr T., Group 5); (Abdelhadi Z. \& Rhita D., Group 10); (Narjiss M. - Kawtar R, Group 14); dominate and monopolize the interactions (with a percentage of 60\%) in their groups and share a lot of information with their colleagues. These students play the role of orchestrators within their groups. Figure 5 shows us the performance of all groups by calculating the average of quantitative indicators cited above. The histogram indicates that there is heterogeneity within some groups, especially the groups 1, 2, 8 and 13 .

\section{F. The reconstitution of groups}

By the end of the fifth week, we have made a new reconstruction of the groups considering the heterogeneity of some of them. The constitution was done in an automatic manner according to our algorithm [33]. Each group will have an average following quantitative indicators that we have exploited. The idea of this algorithm is to swap the learners between groups until the standard deviation of the average of the group tends to 0 . Once the new groups are built, we observed the evolution of and collaboration between learners. Table IV shows the distribution of learners after the reconstitution of groups.

The first observation that we made during the last three weeks is there has been a lot of participations in the forum and a considerable number of shares and documents deposited in the forum and the internal mail by each group as shown in Table III and described in Figure 6. We also noticed that the leaders have played well their roles of orchestrators within their groups. This observation is the result of a comparison of the performances of a few learners before and after reconstitution of groups. 


\section{घGroup 1 aroup $2 \square$ Group $3 \square$ Group 4 घroup $5 \square$ Group $6 \square$ Group 7 \\ घroup 8 Group $9 \square$ Group 10 Group 11 Group 12 Group 13 Group 14}

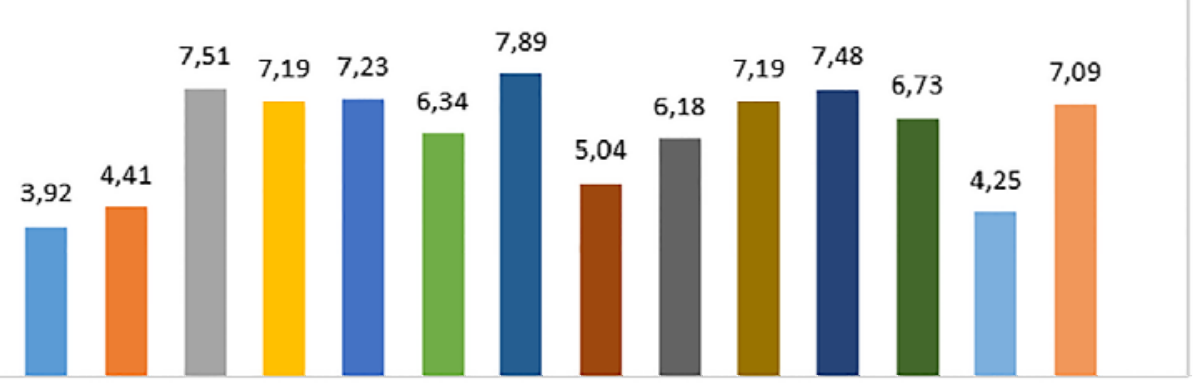

Fig. 5. Average of quantitative indicators of each group in the first five weeks

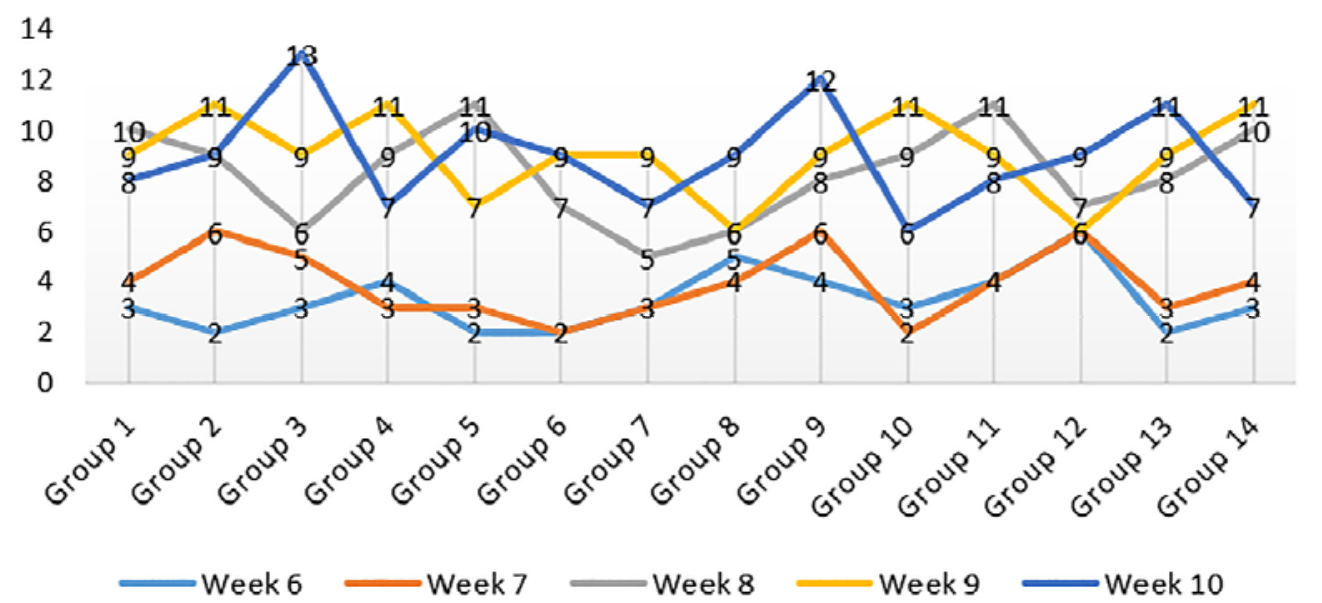

Fig. 6. Number of messages exchanged on the forums and the internal mail for each new group

TABLE III. The Number of messages exchanged and documents shared for each group during the five last weeks

\begin{tabular}{|c|c|c|c|c|c|}
\hline Groups & Week 6 & Week 7 & Week 8 & Week 9 & Week 10 \\
\hline Group 1 & 3 & 4 & 10 & 9 & 8 \\
\hline Group 2 & 2 & 6 & 9 & 11 & 9 \\
\hline Group 3 & 3 & 5 & 6 & 9 & 13 \\
\hline Group 4 & 4 & 3 & 9 & 11 & 7 \\
\hline Group 5 & 2 & 3 & 11 & 7 & 10 \\
\hline Group 6 & 2 & 2 & 7 & 9 & 9 \\
\hline Group 7 & 3 & 3 & 5 & 9 & 7 \\
\hline Group 8 & 5 & 4 & 6 & 6 & 9 \\
\hline Group 9 & 4 & 6 & 8 & 9 & 12 \\
\hline Group 10 & 3 & 2 & 9 & 11 & 6 \\
\hline Group 11 & 4 & 4 & 11 & 9 & 8 \\
\hline Group 12 & 6 & 6 & 7 & 6 & 9 \\
\hline Group 13 & 2 & 3 & 8 & 9 & 11 \\
\hline Group 14 & 3 & 4 & 10 & 11 & 7 \\
\hline
\end{tabular}


TABLE IV. The distribution of learners on groups according to the result of the sociogram

\begin{tabular}{|c|c|}
\hline Groups & Members \\
\hline Group 1 & Badr T. - Hamza B. - Otman H. - Ali E. - Mohamed M. - Imane B. \\
\hline Group 2 & Hamza R. - Abdelkrim S. - Mohammed K. - Kaoutar B. - Fatima T. - Soukaina C. \\
\hline Group 3 & Imane E. - Hossam E. - Meryem S. - Mehdi B. - Fatima C. - Ismail K. \\
\hline Group 4 & Achraf A. - Nouha E. - Hicham E. - Mountasser T. - Iliass L. - Hamza C. \\
\hline Group 5 & M'hammed T. - Nouhaila T. - Nada E. - Ahmed H. - Youssouf T. - Mehdi G. \\
\hline Group 6 & Amine A. - Zainab D. - Nasreddine L. - Zaid L. - Abderrahmane R. - Yassir Q. \\
\hline Group 7 & Marcel M. - Lyna L. - Ibtissem L. - Soukaina K. - Mounssif G. - Hamza A. \\
\hline Group 8 & Meriem T. - Yassine M. - Reda E. - Youness O. - El Mehdi J. - Grace N. \\
\hline Group 9 & Kawtar R. - Abdallah T. - Mehdi Z. - Marouane B. - Sohaib A. - Taha S. \\
\hline Group 10 & Rhita D. - Chaimae E. - Yassine Z. -Mouhcine M. - Khalid H. - El Mehdi Z. \\
\hline Group 11 & Koniba F. - Tefela I. - Rabab B. - Khalid E. - Amine O. - Anas R. \\
\hline Group 12 & Ghita N. - Habiba C. - Wail J. - Ayoub L. - Mohamed E. - Ahmed Z. \\
\hline Group 13 & Abdelhadi Z. - Aissam B. - Oussama I. - Mustapha A. - Youssef H. - Marwan B. \\
\hline Group 14 & Narjiss M. - Ismail B. - M'hamed E. - Majda T. - Azzeddine A. - Amjad J. \\
\hline
\end{tabular}

\section{G. Debate on the Research Results}

The study we presented shows that learners had to work remotely via an online learning platform. In the absence of a tutor who can direct and guide them, they have the challenge and were able to manage this new learning situation. These learners have used virtual interactions and exchanges in a discussion forum and internal mail to ask for help, explain, share and learn in order to provide a final work.

Some learners may produce nothing if there is an absence of a cohesion in the group. This lack of cohesion includes the absence of a leader in the group who is defined here as one who fosters a collaborative environment among the group, helps members assess and improve upon their collaboration, monitors the members' participation, provides process structure in discussions and directs the sequence of activities. All these factors can negatively affect the process of discussion, sharing and collaboration (Group Case 1,2 \& 13) before the reconstitution of groups.

Figure 7 shows the performance of all the new groups by recalculating the average of quantitative indicators cited above. The histogram indicates that there is an improvement and an evolution compared to the first constitution of groups. It shows also that there is some kind of stability and homogeneity between groups, this is due to the role played by the presumed leaders, especially vis-à-vis the learners (Badr T., Hamza R. \& Abdelhadi Z.)
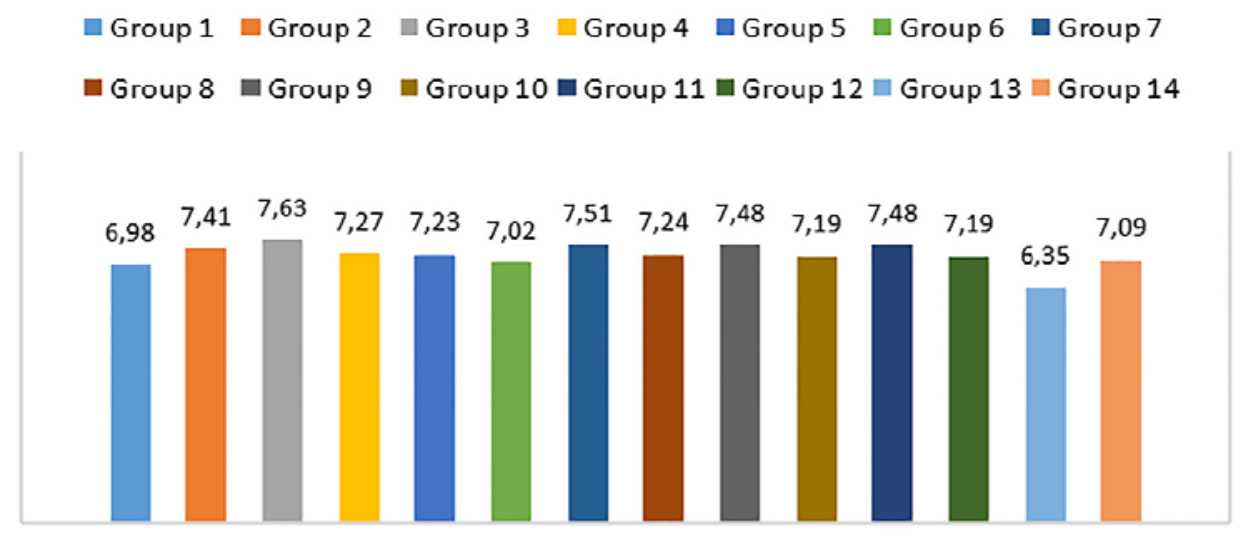

Fig. 7. The Average of quantitative indicators of each group in the last five weeks 


\section{VI.CONCLUSION}

Designers, researchers and tutors are usually involved in the analysis of data gathered at the beginning, during or at the end of learning processes with the aim of gaining a better understanding of the process itself. Tutors are more interested in capturing each single student or group's performances during the course, usually for monitoring and assessment purposes. This analysis must be performed in real time to allow prompt intervention.

Our work aims to find a cohesion and a significant motivation within a group through an online learning platform. This homogeneity can only be built if learners have the prerequisites for remote collaborative work. Moodle platform allows the learners to behave in the same way as face-to-face learning situations and have the same behavioral patterns as those adopted in the conventional group (planning questions, answers, clarifications and comments). The number of chat sessions, of forums attended, of documents uploaded and downloaded, of answers to other student's messages and of messages sent by individual learners can lead to fruitful collaboration, which is synonymous with good quality work. Such indicators allow to detect learners and groups who face difficulties and give an idea about learners who can play the role of a leader within a group.

This work allowed us to test our algorithm from a functional and technical point of view and also identifies real variables from a collaborative online learning. It also allowed us to evaluate several indicators proposed for this experiment and based on three-dimensional model that includes a participative, an interactive and a social dimension.

To conclude, even if the approach proposed here may assist the tutor to rebuild the groups that face difficulties, new indicators should be worked out not only to enrich our approach, but also to pursue different analysis objectives and suit different learning contexts.

\section{REFERENCES}

[1] M. Miled, «Vers une mise en relation des activités d'édition et de navigation dans les ressources d'apprentissage: cas de l'apprentissage d'un langage de programmation,» RJC EIAH 2012, pp. 75--80, Mai 2012.

[2] M. Salihoun, F. Guerouate et M. Sbihi, «The Exploitation of Traces Serving Tutors for the Reconstruction of Groups within a CBLE,» Procedia - Social and Behavioral Sciences, vol. 152, pp. 219--226, October 2014.

[3] F. Mingyu et T. H. Neil, «Informing Teachers Live about Student Learning: Reporting in the Assistment System,» chez The 12th Annual Conference on Artificial Intelligence in Education Workshop on Usage Analysis in Learning Systems, 2003.

[4] L. France, H. Jean-Mathias, J.-C. Marty, T. Carron et J. Heili, «Monitoring Virtual Classroom: Visualization Techniques to Observe Student Activities in an e-Learning System.,» In Proceedings of the Sixth IEEE International Conference on Advanced Learning Technologies, pp. 716--720, 2006.

[5] K. Stefanov et E. Stefanova, «Analysis of the usage of the Virtuoso system,» chez AIED Workshop on Usage Analysis in Learning Systems, Amsterdam, Netherlands, 2005.

[6] C. Reffay et T. Chanier, «Mesurer la cohésion d'un groupe d'apprentissage en formation à distance,» chez Environnements Informatiques pour l'Apprentissage Humain 2003, Strasbourg, France, 2003.

[7] D. Peraya, Chapitre 5. De la correspondance au campus virtuel: formation à distance et dispositifs médiatiques., De Boeck Supérieur, 2002.

[8] D. Keim, G. Andrienko, J.-D. Fekete, C. Görg, J. Kohlhammer et G. Melançon, «Visual analytics: Definition, process, and challenges,» chez Information visualization, Springer, 2008, pp. 154--175.

[9] M. Sedlmair, P. Isenberg, D. Baur, M. Mauerer, C. Pigorsch et A. Butz, «Cardiogram: visual analytics for automotive engineers,» chez Proceedings of the SIGCHI conference on Human factors in computing systems, 2011.

[10] J. Zhao, F. Chevalier et R. Balakrishnan, «Kronominer: using multi-foci navigation for the visual exploration of time-series data,» chez Proceedings of the SIGCHI Conference on Human Factors in Computing Systems, 2011.

[11] J. Hardy, S. Bates, J. Hill et M. Antonioletti, «Tracking and visualisation of student use of online learning materials in a large undergraduate course,» chez International Conference on Web-Based Learning, 2007.

[12] R. Mazza et C. Milani, «Exploring Usage Analysis in Learning Systems: Gaining Insights From Visualisations,» Communication in the Workshop on Usage analysis in learning systems, the twelfth International Conference on Artificial Intelligence in Education, pp. 65--72, 2005

[13] H.-C. Schmitz, M. Scheffel, M. Friedrich, M. Jahn, K. Niemann et M. Wolpers, «CAMera for PLE,» chez European Conference on Technology Enhanced Learning, 2009.

[14] M. Wolpers, J. Najjar, K. Verbert et E. Duval, «Tracking actual usage: the attention metadata approach,» Educational Technology \& Society, vol. 10, n⿳\%13, pp. 106-121, 2007.

[15] H. Zhang, K. Almeroth, A. Knight, M. Bulger et R. Mayer, «Moodog: Tracking students’ online learning activities,» chez Proceedings of World conference on educational multimedia, hypermedia and telecommunications, 2007.

[16] S. Govaerts, K. Verbert, E. Duval et A. Pardo, «The student activity meter for awareness and self-reflection.,» chez CHI'12 Extended Abstracts on Human Factors in Computing Systems., 2011.

[17] A. Martinez, Y. Dimitriadis, E. Gomez, B. Rubia et P. de la Fuente, «Combining qualitative and social network analysis for the study of classroom social interactions,» Computers and Education, Elsevier, vol. 4, pp. 353--368, 2003.

[18] G. Gagnon, S. Gravel, J. Tremblay et C. de Jonquière, «Integrating affective dimension to educational training,» TREFIE, Cégepde Jonquière, 2013.

[19] S. Sugawara et N. Arai, «Tool for Visualizing Students Interaction on a Learning Management System,» chez Web-based Education, ACTA Press, 2010

[20] C. Reffay et L. Lancieri, «Quand l'analyse quantitative fait parler les forums de discussion,» Revue des Sciences et Technologies de l'Information et de la Communication pour l'Education et la Formation (STICEF), vol. 13, pp. 255--288, 2006.

[21] A. Jaillet, Peut-on repérer les effets de l'apprentissage collaboratif à distance, vol. 3, Strasbourg: Lavoisier, 2005, pp. 49 --66. 
[22] S. Olga C, R. E. G. Antonio et B. Jesus G, «Helping the tutor to manage a collaborative task in a web-based learning environment,» chez AIED2003 Supplementary Proceedings, 2003.

[23] P. Dillenbourg, «Framework for integrated learning,» The European Commission, DG INFSO, under contract No. IST 507838, 2004.

[24] C. Glahn, M. Specht et R. Koper, «Visualisation of interaction footprints for engagement in online communities,» Educational Technology \& Society, vol. 12, n⿳\% \%13, pp. 44-57, 2009.

[25] I. Oumaira, R. Messoussi et R. Touahni, «interactions, Instrumentation des activités des tuteurs à l'aide d'un système multi-agents d'analyse automatique des,» Revue Africaine de la Recherche en Informatique et Mathématiques Appliquées, vol. 14, pp. 125--147, 2011.

[26] P. Pernelle, M. J. Charles et T. Carron, «From traces to indicators for serious games: case study concerning a new way to introduce product lifecycle management,» International Journal of Learning Technology, vol. 8, n%12, p. 127, 2013.

[27] C. E. Hollander, An introduction to sociogram construction, Snow Lion Press, 1978.

[28] D. R. Garrison, T. Anderson et W. Archer, «Critical inquiry in a text-based environment: Computer conferencing in higher education,» The internet and higher education, vol. $2, \mathrm{n}^{\circ} \% 12$, pp. 87-105.

[29] F. Henri, «Computer conferencing and content analysis,» chez Collaborative learning through computer conferencing, Springer, 1992, pp. 117-136.

[30] M. Wang, «Correlational analysis of student visibility and performance in online learning,» Journal of Asynchronous Learning Networks, vol. 8, n%14, pp. 71-82, 2004.

[31] M. T. Chi, «Quantifying qualitative analyses of verbal data: A practical guide,» The journal of the learning sciences, vol. 6, n $\% 13$, pp. 271--315, 1997.

[32] Moodle, «Moodle - Open-source learning platform | Moodle.org,» 2017. [En ligne]. Available: https://moodle.org/.

[33] M. Salihoun, F. Guerouate, N. Berbiche et M. Sbihi, «How to Assist Tutors to Rebuild Groups Within an ITS by Exploiting Traces. Case of a Closed Forum.,» International Journal of Emerging Technologies in Learning (iJET), vol. 12, nº \%13, pp. 169--181, 2017.

\section{AUTHOR PROFILE}

Salihoun Mohammed was born in Rabat, in 1986. He is a PhD student at Mohamed V University in Rabat, Morocco. He received a Master's degree in Computer Science from Mohamed V University in Rabat in 2011. His research interests are E-learning, Tracking and Software Engineering.

Guerouate Fatima is a Research professor at LASTIMI laboratory and Professor in the Department of Computer Sciences at the Superior School of Technologies of Salé, Mohammed V University in Rabat, Morocco. She is interested in E-learning and Serious games.

Sbihi Mohamed received the Master degree and the Doctorate in Automatic and Information Processing at Mohammed V University in Rabat. He is interested in Image processing and Data analysis. He is the author or coauthor of some papers in international conferences and journals. 